http://www.jumdc.com/

\title{
Evaluation of oral hygiene Knowledge and Practices among patients visiting a Public Dental Institute
}

\author{
Naveed Irfan a , Agha Taymoor Ali ${ }^{\text {, }}$, Suneel Kumar Punjabi c, Mowaffaq Abdullmomen Al Absi d, Talha Asad Khan ${ }^{\mathrm{e}}$, \\ Arsalan Ahmed ${ }^{\mathrm{f}}$ \\ ${ }^{a}$ Associate Professor Department of Community Dentistry, Isra Dental College Isra University Hyderabad. \\ ${ }^{\mathrm{b}}$ Assistant Professor, Department of Operative Dentistry, Ishrat Ul Ebad Institute of Oral Health Sciences, Dow University of \\ Health Sciences, Ojha Campus, Karachi. \\ ${ }^{\mathrm{c} A s s o c i a t e}$ Professor, Department of Oral and Maxillofacial Surgery, Institute of Dentistry Liaquat University of Medical \& \\ Health Sciences, Jamshoro. \\ dAssociate Professor, Department of Operative Dentistry, Inchrage Endodontic Department Isra Dental College,

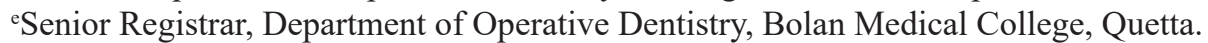 \\ ${ }_{\mathrm{f}}^{\mathrm{f}}$ Assistant Professor/ Head Department of Periodontics at Avicenna Medical \& Dental College Lahore. \\ *Corresponding Author's e-mail: dr.naveedirfan82@gmail.com
}

\section{ABSTRACT}

BACKGROUND \& OBJECTIVE: Knowledge regarding oral hygiene and routine practices of maintaining that hygiene contributes to good oral and overall health of a person. The objective of the study was to evaluate the oral hygiene perception and practices among patients belonging to rural and urban areas visiting a public dental institute.

METHODOLOGY: A descriptive cross-sectional study was conducted at the dental outpatient department (OPD) of the Institute of Dentistry Liaquat University Jamshoro Sindh from June-December 2019. All patients who reported the dental OPD during the duration of the study belonging to either gender and age 18-70 years were included in the study. While those who reported in emergency with painful conditions and chronic diseases like diabetes mellitus, hypertension, etc., were excluded. A written questionnaire was used to collect participant's information including socio-demographic details and information related to oral hygiene perceptions and practices. Data was analyzed by SPSS version 24.0.

RESULTS: The mean age of participants was $28.94 \pm 9.84$ years, with an age range of 19-58 years. There was a statistically significant difference $(\mathrm{p}<0.05)$ between female and male participants regarding knowledge and perception of the role of oral cleaning in decay prevention, different methods of preventing dental problems, and the role of remnants of sweet food in damaging teeth. While statistically significant difference $(p<0.05)$ in the type of toothbrush used, brushing technique, and frequency of changing toothbrush was demonstrated between participants belonging to rural and urban regions.

CONCLUSION: Knowledge and routine practices regarding oral hygiene are much lower in residents of the rural region compared with the urban region.

KEYWORDS: Dental Health Surveys, Oral Hygiene, Knowledge.

\section{INTRODUCTION}

Oral diseases are considered a major public health concern, owing to their high prevalence and effects on an individual's quality of life in causing agony, distress, defacement, and even mortality, affecting more than 3 billion people worldwide ${ }^{[1]}$. Oral diseases, like most chronic diseases in general are directly linked to lifestyle and in the last few years, a decline in caries prevalence is being observed in the epidemiological profile of dental caries ${ }^{[3]}$. This occurs as a result of oral health promotion programs, and fluoridated drinking water. These factors are directly related to reductions in caries and tooth extractions, clearly supporting the view that dental caries can be reduced by controlling risk factors ${ }^{[4]}$.

The behavior of an individual regarding oral hygiene and seeking oral health care depends on a multitude of factors. Evidence has shown that basic knowledge of oral health influences oral care practice in a positive manner ${ }^{[5]}$. Appropriate knowledge regarding oral health not only changes the attitude but also encourages people to maintain proper oral health hygiene practices ${ }^{[6]}$.

Irfan N, Ali AT, Kumar S, Absi MAA, Khan TA, Ahmed A. Evaluation of oral hygiene knowledge and practices among patients visiting a public dental institute. Journal of University Medical \& Dental College. 2021;12(4):270-274. 
Moreover, patients have shown to adhere to oral healthcare regimens and have shown more compliance towards oral healthcare routines when properly informed and positively encouraged ${ }^{[6]}$. Studies have demonstrated that in the absence of proper knowledge, especially among the majority of people residing in rural areas and negligent behavior of the urban population commonly results in a number of dental diseases ${ }^{[7,8]}$.

This is also supported by the fact that lack of proper information or even misinformation about oral health is one of the leading causes of non-adherence to oral healthcare and oral hygiene routines ${ }^{[9]}$.

The change to a healthy attitude and practice can be achieved by giving adequate information and motivation to the subjects ${ }^{[10]}$.

This study was designed to evaluate the oral hygiene perception and practices among patients belonging to rural and urban areas visiting a public dental institute. The information of this study can be beneficial in future oral health planning and promotional strategies.

\section{METHODOLOGY}

This cross-sectional study was undertaken at the dental Outpatient department (OPD) of the Institute of Dentistry, Liaquat University of Medical and Health Sciences, Jamshoro, from June 2019 till December 2019. All patients belonging to either gender and aged from 18 to 70 years that visited the dental OPD during the duration of the study were included. While those who reported in emergency and/or with chronic diseases like diabetes mellitus, hypertension, etc., were excluded. The sample size was derived by the formula $\mathrm{n}=\mathrm{Z} 2 \mathrm{P}(1-\mathrm{P}) / \mathrm{d} 2{ }^{[11]}$.

A sample size of 300 was obtained. Non-probability consecutive sampling technique was applied for the selection of study participants. Ethical clearance was obtained from the institutional ethical committee of Isra University Hyderabad, and permission for the collection of information was obtained from the in-charge of the Institute of Dentistry, Liaquat University of Medical and Health Sciences, Jamshoro. Written consent was obtained from each participant who fulfilled the selection criteria.

A close-ended questionnaire comprising of two parts was handed over to each participant. The first part of the questionnaire consisted of the socio-demographic profile of the individual, while the second part consisted of close-ended questions about the participant's oral hygiene perceptions and practices. The questionnaire was validated by the epidemiologist in the university. The questionnaire was initially framed in English language and then translated into the local languages (Urdu and Sindhi). To test the reliability of the questionnaire, a pilot study was conducted. The participants of the study were asked to fill the questionnaire themselves, while those who faced difficulty in reading the local language, assistance was provided by their companions or fellow participants. A strict protocol of confidentiality was maintained to avoid any sort of bias. Participation of all participants was voluntary, and no incentive was offered. The data was entered and analyzed using Statistical Package for the Social Sciences (SPSS) version 24.0. The gender and residence difference in oral health perception and practices among the participants was evaluated using Chi-square statistics and/or Fisher's exact test, whichever applicable. $\mathrm{p}<0.05$ was considered to be statistically significant.

\section{RESULTS}

A total of 300 participants were recruited in the present study. Out of the total participants, the majority were male. The mean age of the participants was $28.94 \pm 9.84$ years, with an age range between 19 and 58 years. Over three-fourths of the participants were young adults, i.e., less than or equal to the age of 40 years, while the majority of them were from urban areas (Table-I).

Table-I: Socio-demographic distribution of study participants $(\mathbf{n}=\mathbf{3 0 0})$.

\begin{tabular}{cc}
\hline Gender & F (\%) \\
\hline Male & $162(54.0)$ \\
Female & $138(46.0)$ \\
\hline Age group (years) & $\mathbf{F ~ ( \% )}$ \\
$\leq 20$ & $60(20.0)$ \\
$21-30$ & $120(40.0)$ \\
$31-40$ & $82(27.3)$ \\
41 and above & $38(12.7)$ \\
Residence & $\mathbf{F}(\%)$ \\
\hline Rural & $124(41.3)$ \\
\hline Urban & $176(58.7)$ \\
\hline
\end{tabular}

Table-II demonstrates the knowledge and perception of study participants about oral hygiene. Most of the participants knew about the importance of oral health and its impact on the general health of a person. Male participants responded positively to this question compared to the females though the difference between both genders to this question was insignificant. There was a statistically significant difference $(p<0.05)$ between female and male participants in terms of knowledge and perception of the role of oral cleaning in decay prevention, different methods of preventing dental problems and the role of remnants of sweet food in damaging teeth. A statistically significant difference $(p<0.05)$ in oral health knowledge and perception was demonstrated between rural and urban regions participants (Table-II). Table-III presents the distribution of participants in relation to gender and region according to their oral hygiene habits/practices. Most of the study participants were using toothbrush and paste. A statistically significant difference $(p<0.05)$ was observed between males and females as well as between rural and urban participants. A total of 177 (59.0) participants were using toothpaste, of which 118 (66.7) were not noticing its type, whereas $37(21.0)$ reported that they were using herbal toothpaste and 22(12.4) were using fluoridated toothpaste. Statistically, a significant $(\mathrm{p}<0.05)$ difference was observed between male and female as well as rural and urban participants regarding the duration of brushing and frequency of dentist visits. 


\section{Irfan N, Ali AT, Kumar $S$,}

Additionally, a statistically significant difference $(\mathrm{p}<0.05)$ in the use of interdental aid, type of toothbrush used, brushing technique, and frequency of changing toothbrush was demonstrated between participants belonging to rural and urban regions (Table-III).

Table-II: Comparison of Oral hygiene knowledge between study participants $(n=300)$.

\begin{tabular}{|c|c|c|c|c|c|c|}
\hline & $\begin{array}{c}\text { Male } \\
162\end{array}$ & $\begin{array}{c}\text { Female } \\
138\end{array}$ & p-value & $\begin{array}{c}\text { Rural } \\
124\end{array}$ & $\begin{array}{c}\text { Urban } \\
176\end{array}$ & p-value \\
\hline $\begin{array}{l}\text { Does oral health have any impact on overall } \\
\text { health } \\
\text { - Yes } \\
\text { - No } \\
\text { - Don't Know }\end{array}$ & $\begin{array}{l}80(49.3) \\
38(23.4) \\
44(27.1)\end{array}$ & $\begin{array}{l}60(43.4) \\
26(19.0) \\
52(37.6)\end{array}$ & 0.14 & $\begin{array}{l}31(25.0) \\
42(34.0) \\
51(41.0)\end{array}$ & $\begin{array}{l}109(62.0) \\
22(12.5) \\
45(25.5)\end{array}$ & $<0.001$ \\
\hline $\begin{array}{l}\text { Clean mouth can prevent tooth decay } \\
\text { - } \quad \text { Yes } \\
\text { - } \quad \text { No }\end{array}$ & $\begin{array}{c}136(84.0) \\
26(16.0)\end{array}$ & $\begin{array}{c}103(74.6) \\
35(25.4)\end{array}$ & 0.045 & $\begin{array}{l}90(72.6) \\
34(27.4)\end{array}$ & $\begin{array}{c}149(84.7) \\
27(15.3)\end{array}$ & 0.010 \\
\hline $\begin{array}{ll}\text { Methods to prevent dental problems } \\
\text { - } & \text { Avoiding sweet and sticky food } \\
\text { - } & \text { Brushing regularly } \\
\text { - } & \text { Mouth rinsing after meals } \\
\text { - } & \text { Regularly visiting a dentist }\end{array}$ & $\begin{array}{l}18(11.1) \\
82(50.6) \\
36(22.3) \\
26(16.0)\end{array}$ & $\begin{array}{l}37(26.8) \\
57(41.3) \\
28(20.3) \\
16(11.6)\end{array}$ & 0.005 & $\begin{array}{l}29(23.4) \\
39(31.4) \\
37(30.0) \\
19(15.2)\end{array}$ & $\begin{array}{c}26(14.7) \\
100(57.0) \\
27(15.3) \\
23(13.0)\end{array}$ & $<0.001$ \\
\hline 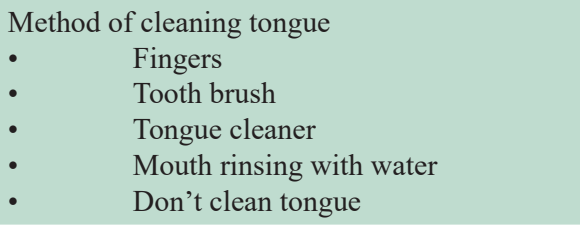 & $\begin{array}{c}21(13.0) \\
19(11.7) \\
10(6.2) \\
38(23.4) \\
74(45.7)\end{array}$ & $\begin{array}{c}19(13.8) \\
22(16.0) \\
12(8.7) \\
18(13.0) \\
67(48.5)\end{array}$ & 0.19 & $\begin{array}{l}29(23.4) \\
10(8.0) \\
5(4.0) \\
16(13.0) \\
64(51.6)\end{array}$ & $\begin{array}{c}11(6.2) \\
31(17.6) \\
17(9.6) \\
40(22.8) \\
77(43.8)\end{array}$ & $<0.001$ \\
\hline $\begin{array}{l}\text { Retention of sweet food on teeth damage teeth } \\
\text { - } \\
\text { - }\end{array}$ & $\begin{array}{c}84(52.0) \\
16(9.8) \\
62(38.2)\end{array}$ & $\begin{array}{l}40(29.0) \\
15(11.0) \\
83(60.0)\end{array}$ & $<0.001$ & $\begin{array}{l}56(45.1) \\
17(13.7) \\
51(41.2)\end{array}$ & $\begin{array}{c}68(38.6) \\
14(8.0) \\
94(53.4)\end{array}$ & 0.06 \\
\hline $\begin{array}{ll}\text { In case of bleeding gums } \\
\text { - } & \text { Avoid brushing } \\
\text { - } & \text { Visit to doctor } \\
\text { - } & \text { Use mouthwash } \\
& \text { No need to do anything }\end{array}$ & $\begin{array}{l}23(14.2) \\
42(26.0) \\
38(23.4) \\
59(36.4)\end{array}$ & $\begin{array}{l}31(22.4) \\
40(29.0) \\
19(13.8) \\
48(34.8)\end{array}$ & 0.07 & $\begin{array}{c}40(32.2) \\
15(12.1) \\
12(9.7) \\
57(46.0)\end{array}$ & $\begin{array}{c}14(8.0) \\
67(38.0) \\
45(25.6) \\
50(28.4)\end{array}$ & $<0.001$ \\
\hline
\end{tabular}

\section{DISCUSSION}

It is a very difficult task to define the quality of life of an individual or society depending on oral health since the basic concept itself is very vague, elusive, subjective, multidimensional, and without definitive boundaries ${ }^{[12]}$. The level of literacy also influences the consistency of the patients' routine dental practices in maintaining their oral hygiene. Oral health has thus remained an ignored entity and an unrealized issue in Pakistani society. It poses a threat globally in terms of the general well-being and providing a good quality of life to an individual ${ }^{[13,14]}$. It remains well established that the oral cavity becomes the gateway for many systemic diseases as also the first signs and symptoms of many systemic diseases find their first manifestations in the oral cavity ${ }^{[15]}$.

The sample population in the present study consisted of a greater proportion of males, with $54.0 \%$ visiting the dental OPD in the six months during the survey. This data is on par with previous studies, with a higher rate of utilization by male patients ${ }^{[9,14,16]}$. While some studies reported that a higher proportion of participants in their study were female $[17,18]$.

Toothbrushes and pastes have been accredited globally as the means for everyday oral hygiene routines. In this study, two-thirds $(75 \%)$ of the total population were using a toothbrush to maintain oral hygiene, which is consistent with the findings reported by Sen et al. ${ }^{[14]}$. Additionally, a higher prevalence of toothbrush usage of $94.4 \%, 90.0 \%$, and $87.0 \%$ have been reported ${ }^{[12]}$ respectively. While a lower prevalence of toothbrush usage, i.e. $69 \%$ and $42 \%$, has been reported ${ }^{[15,19]}$.

On comparing the rural with the urban society, more of the urban population $(81.3 \%)$ tended to use a toothbrush for maintaining oral hygiene than the rural society $(66.9 \%)$. This finding is consistent with the findings who reported that healthier tooth cleaning habits are better reported in the urban than the rural population ${ }^{[12]}$.

This may be because the people residing in rural areas tend to use those techniques which are easily accessible and more comfortable for them due to a lack of awareness of correct oral hygiene measures.

It is interesting to note that brushing the teeth using toothbrush and toothpaste has been the most common method of maintaining oral hygiene, but the frequency of tooth-brushing still lags. In the present study, the number of people brushing their teeth twice daily was $43 \%$. These findings are in line with the findings reported in previously published literature ${ }^{[14,17,19]}$. 


\section{Knowledge and practices of oral hygiene}

A total of $22.6 \%$ of participants reported that they used to change their brush when the bristles get destroyed. These findings are consistent with that done by Sen et al ${ }^{[14]}$. This may be due to the socioeconomic standards of the participants who participated in this study. This is further justified by our results which portray a highly statistically significant difference between the rural and the urban population.
A visit to a dentist is still deemed necessary only when in pain. The findings of our study corroborate this observation. Only $10 \%$ of people had visited a dentist in the last 1 year while about $65 \%$ had visited only when having any dental problem like; pain.

Multiple reasons may be allocated for the same, including lack of awareness, motivation, or economic condition.

Table-III: Comparison between oral hygiene habits / practices among study participants $(\mathbf{n}=\mathbf{3 0 0})$.

\begin{tabular}{|c|c|c|c|c|c|c|}
\hline & $\begin{array}{c}\text { Male } \\
162\end{array}$ & $\begin{array}{c}\text { Female } \\
138\end{array}$ & p-value & $\begin{array}{c}\text { Rural } \\
124\end{array}$ & $\begin{array}{c}\text { Urban } \\
176\end{array}$ & p-value \\
\hline $\begin{array}{ll}\text { Dental Cleaning material and method } \\
\text { - } & \text { Toothbrush and toothpaste } \\
\text { - } & \text { Toothbrush and powder } \\
\text { - } & \text { Miswak } \\
\text { - } & \text { Finger and toothpaste/powder }\end{array}$ & $\begin{array}{c}98(60.5) \\
32(19.7) \\
20(12.3) \\
12(7.4)\end{array}$ & $\begin{array}{l}60(43.5) \\
36(26.1) \\
24(17.4) \\
18(13.0)\end{array}$ & $0.028^{*}$ & $\begin{array}{l}50(40.3) \\
33(26.6) \\
20(16.1) \\
21(17.0)\end{array}$ & $\begin{array}{c}108(61.3) \\
35(20.0) \\
24(13.6) \\
9(5.1)\end{array}$ & $0.000 *$ \\
\hline $\begin{array}{ll}\text { Interdental aids used } \\
\text { - } & \text { Dental Floss } \\
\text { - } & \text { Toothpick } \\
\text { - } & \text { Mouthwash } \\
\text { - } & \text { Nothing }\end{array}$ & $\begin{array}{c}12(7.4) \\
15(9.2) \\
21(13.0) \\
114(70.4)\end{array}$ & $\begin{array}{l}10(7.2) \\
16(11.6) \\
18(13.1) \\
94(68.1)\end{array}$ & 0.929 & $\begin{array}{l}7(5.6) \\
12(9.7) \\
9(7.3) \\
96(77.4)\end{array}$ & $\begin{array}{c}15(8.5) \\
19(10.8) \\
30(17.1) \\
112(63.6)\end{array}$ & $0.040 *$ \\
\hline $\begin{array}{ll}\text { - } & \text { Toothbrush type used } \\
\text { - } & \text { Hard Medium } \\
\text { - } & \text { Soft } \\
\text { - } & \text { Don't Know }\end{array}$ & $\begin{array}{c}51(31.4) \\
11(6.8) \\
66(40.7) \\
34(21.1)\end{array}$ & $\begin{array}{c}38(27.5) \\
12(8.7) \\
49(35.5) \\
39(28.3)\end{array}$ & 0.40 & $\begin{array}{l}36(27.4) \\
8(8.0) \\
37(30.0) \\
43(34.6)\end{array}$ & $\begin{array}{l}53(30.1) \\
15(8.5) \\
78(44.3) \\
30(17.1)\end{array}$ & $0.003 *$ \\
\hline $\begin{array}{l}\text { Frequency of daily brushing } \\
\text { - } \\
\text { - } \\
\text { - }\end{array}$ & $\begin{array}{c}100(61.7) \\
43(26.5) \\
10(6.2) \\
9(5.5)\end{array}$ & $\begin{array}{c}75(54.4) \\
41(29.7) \\
14(10.1) \\
8(5.8)\end{array}$ & 0.48 & $\begin{array}{c}63(50.8) \\
42(33.8) \\
7(5.6) \\
10(8.0)\end{array}$ & $\begin{array}{c}110(62.6) \\
42(23.8) \\
17(9.6) \\
7(4.0)\end{array}$ & $0.047 *$ \\
\hline $\begin{array}{l}\text { Frequency of changing brush } \\
\text { - } \quad \text { Once in a year } \\
\text { - } \quad \text { Once in } 6 \text { months } \\
\text { - } \quad \text { Once in } 3 \text { months } \\
\text { - } \quad \text { When bristles get destroyed }\end{array}$ & $\begin{array}{l}90(55.6) \\
16(10.0) \\
20(12.3) \\
36(22.1)\end{array}$ & $\begin{array}{c}81(58.7) \\
13(9.4) \\
12(8.6) \\
32(23.3)\end{array}$ & 0.76 & $\begin{aligned} 68 & (54.8) \\
9 & (7.2) \\
9 & (7.2) \\
38 & (30.6)\end{aligned}$ & $\begin{array}{l}103(73.8) \\
20(11.3) \\
23(13.0) \\
30(17.0)\end{array}$ & $0.000 *$ \\
\hline $\begin{array}{l}\text { Duration of brushing } \\
\text { - } \quad 1-2 \text { minutes } \\
\text { - } \quad 2-5 \text { minutes } \\
\text { - } \quad 5-10 \text { minutes } \\
>10 \text { minutes }\end{array}$ & $\begin{array}{l}44(27.1) \\
30(18.5) \\
76(47.0) \\
12(7.4)\end{array}$ & $\begin{array}{l}67(48.5) \\
20(14.5) \\
29(21.0) \\
22(16.0)\end{array}$ & $0.000 *$ & $\begin{array}{l}25(20.2) \\
19(15.3) \\
57(46.0) \\
23(18.5)\end{array}$ & $\begin{array}{l}86(49.0) \\
31(17.6) \\
48(27.2) \\
11(6.2)\end{array}$ & $0.000 *$ \\
\hline $\begin{array}{ll}\text { Most frequent brushing Method used } \\
\text { - } & \text { Horizontal } \\
\text { - } & \text { Vertical } \\
\text { - } & \text { Circular }\end{array}$ & $\begin{array}{l}73(45.1) \\
64(39.5) \\
25(15.4)\end{array}$ & $\begin{array}{l}58(42.0) \\
64(46.4) \\
16(11.6)\end{array}$ & 0.40 & $\begin{array}{l}44(38.7) \\
53(43.5) \\
27(17.8)\end{array}$ & $\begin{array}{l}87(47.2) \\
75(42.0) \\
14(10.8)\end{array}$ & $0.001 *$ \\
\hline $\begin{array}{l}\text { Frequency of dental visits } \\
\text { - } \\
\text { - } \\
\text { - }\end{array}$ & $\begin{array}{c}20(12.2) \\
16(10.0) \\
11(6.8) \\
115(71.0)\end{array}$ & $\begin{array}{c}28(20.3) \\
10(7.2) \\
19(13.7) \\
81(58.7)\end{array}$ & $0.030^{*}$ & $\begin{array}{c}7(5.6) \\
9(7.2) \\
14(11.3) \\
94(75.8)\end{array}$ & $\begin{array}{c}41(23.3) \\
17(9.6) \\
16(9.1) \\
102(58.0)\end{array}$ & $0.000 *$ \\
\hline
\end{tabular}

\section{CONCLUSION}

It is concluded that oral hygiene knowledge/ perception and practices/habits of the patients are unsatisfactory. Knowledge and routine practices regarding oral hygiene are much lower in residents of the rural region compared with the urban region.

ACKNOWLEDGEMENT: None. CONFLICT OF INTEREST: None. GRANT SUPPORT \& FINANCIAL DISCLOSURE: None.

\section{REFERENCES}

1. James SL, Abate D, Abate KH, Abay SM, Abbafati $\mathrm{C}$, Abbasi N, et al. Global, regional, and national incidence, prevalence, and years lived with disability for 354 diseases and injuries for 195 countries and territories, 1990-2017: a systematic analysis for the Global Burden of Disease Study 2017. The Lancet. 2018;392(10159):1789-1858. Doi: 10.1016/S01406736(18)32279-7

2. Mathivadani V, Ganesh S BA, Arivarasu L. Knowledge and Awareness Of Oral Hygiene Maintenance-A Survey. Journal of Contemporary Issues in Business and Government. 2021;27(2):2634-2642. 
3. Frencken JE, Sharma P, Stenhouse L, Green D, Laverty D, Dietrich T. Global epidemiology of dental caries and severe periodontitis-a comprehensive review. Journal of Clinical Periodontology. 2017;44:S94-S105. Doi: $10.1111 /$ jcpe. 12677

4. Vrbič V, Vrbič M, Petersen PE. Epidemiology of dental caries and disease prevention among 12-year-olds in Slovenia over thirty years (1987-2017). Oral Health Preventive Dentistry. 2020;18:185-196.

5. Barma MD, Indiran MA, Srisakthi D, Kumar P. Influence of socio-economic factors on unmet dental treatment needs among adult population worldwide: a structured review. PalArch's Journal of Archaeology of Egypt/Egyptology. 2020;17(7):1204-1215.

6. Shehzad S, Farooq A, Waheed Z, Maqsood F, Khan I, Kabir SK. Knowledge, attitude \& practice about oral hygiene in students of district peshawar. Pakistan Oral \& Dental Journal. 2020;40(2):80-83.

7. Abdullah I, Alasady M. The impact of socioeconomic status on oral health of southern population in Iraq. Annals of Tropical Medicine and Public Health. 2021;24:205-216.

8. Rad EH, Kavosi Z, Arefnezhad M. Economic inequalities in dental care utilizations in Iran: Evidence from an urban region. Medical Journal of the Islamic Republic of Iran. 2016;30:383.

9. Kapoor D, Gill S, Singh A, Kaur I, Kapoor P. Oral hygiene awareness and practice amongst patients visiting the Department of Periodontology at a Dental College and Hospital in North India. Indian Journal of Dentistry. 2014;5(2):64.

10. Poudel P, Griffiths R, Wong VW, Arora A, Flack JR, Khoo CL, et al. Oral health knowledge, attitudes and care practices of people with diabetes: a systematic review. BMC public health. 2018;18(1):1-12.

11. Priyadarshini S, Perveen Z, Mehrotra A, David SJ, Agarwal A, Kumar A. Prevalence of misconception regarding oral health among the general population of Northern India: A KAP Study. Journal of Medical and Dental Science Research. 2021;8(5):01-6.

12. Durrani F, Rahman F, Sathiananthan MK, Kesarwani S, Galohda A, Borang PO. Oral hygiene practices and knowledge among residents of the trans-varuna region (India): A hospital-based study. Journal of Indian Association of Public Health Dentistry. 2018;16(2):154159.

13. Dawani N, Afaq A, Bilal S. Oral Health Knowledge, Attitude and Practices Amongst Teachers of Public School Set-up of Karach, Pakistan. Journal of the Dow University of Health Sciences (JDUHS). 2013;7(1):1519.

14. Sen N, Mandal A, Bhat N, Asawa K, Sultane P, Chhabra $\mathrm{S}$, et al. Oral Health-related Knowledge, Attitude, and Practices among Patients attending the Department of Public Health Dentistry of a Dental Hospital in Udaipur, India. International Journal of Preventive and Clinical Dental Research. 2017;4:43-49.
15. Jain N, Mitra D, Ashok K, Dundappa J, Soni S, Ahmed S. Oral hygiene-awareness and practice among patients attending OPD at Vyas Dental College and Hospital, Jodhpur. Journal of Indian Society of Periodontology. 2012;16(4):524-528. Doi: 10.4103/0972-124X.106894

16. Singh A, Gambhir RS, Singh S, Kapoor V, Singh J. Oral health: How much do you know?-A study on knowledge, attitude and practices of patients visiting a North Indian dental school. European Journal of Dentistry. 2014;8(1):63-67.

17. Lakdawala YA, Masood S, Khamuani MP, Amna R. Oral hygiene practices- a survey. Pakistan Oral \& Dental Journal. 2018;38(3):349-352.

18. Younus A, Qureshi A. Tooth brush changing frequency and associated socio-demographic and oral hygiene factors among residents of Karachi. Journal of Dentistry and Oral Hygiene. 2016;8(2):4-11.

19. Bangash MFK, Jamroz Khan AH. Oral hygiene practice and awareness among Pakistanis in Riyadh, Saudi Arabia, Pak. Oral Dental Journal. 2013;33(2):350-353.

\section{Author's Contribution:}

Naveed Irfan: Conception, acquisition of data, analysis and interpretation of the

data.

Agha Taymoor Ali: Statistical analysis, and manuscript writing.

Suneel Kumar Punjabi: Analysis, interpretation of the data, and drafting the article.

Talha Asad Khan: Formalization of results and tables. Arsalan Ahmed: Final proofreading and editing of the manuscript. 